\title{
Н.Н. Ефремов
}

\section{Институт гуманитарных исследований и проблем}

малочисленных народов Севера СО РАН, Якутск

\section{Локативные конструкции с показателем дательного падежа в якутском языке}

Аннотащия: В данной статье впервые в якутском языкознании рассматривается структура и семантика локативных конструкций с показателем дательного падежа. Выявляются и описываются элементарные простые и полипредикативные (сложноподчиненные) предложения с указанным падежом, в которых реализуются пространственные отношения.

The paper considers, for the first time, in the Sakha language the structure and semantics of the locative constructions indicating dative case. The author reveals and describes elementary simple sentences and poly-predicative (complex) sentences with the said case where the spatial relations are realized.

Ключевые слова: локативность, конструкция, элементарное простое предложение, падежи, локация, адлокация, делокация, транслокация.

Locativeness, constructions, elementary simple sentence, cases, locations, adlocation, delocation, translocanion.

УДК: 811.512.157'366.54.

Контактная информащия: Якутск, ул. Петровского, 1. ИГИиПМНС СО РАН. Тел. (4112) 351516. E-mail: nik.efrem50@mail.ru.

\section{1. Общая характеристика пространственных конструкций с падежными показателями}

В якутском языке пространственные отношения выражаются формами дательного, исходного, орудного и винительного падежей в составе определенных конструкций. При этом сказуемые обсуждаемых конструкций представляются глаголами и другими предикативными формами с пространственным значением. Это глаголы движения, перемещения, помещения, существования, местонахождения, имена наличия, отсутствия (баар, суох), количественные имена (например, элбэх 'много', ађыйах 'мало') и др. Когда подобные сказуемые оформляются глаголами или именами других лексико-грамматических групп, конструкциями с указанными падежами выражаются несобственно-пространственные - предметные, обстоятельственные - значения.

Конструкции с названными падежами функционируют в качестве элементарных простых или полипредикативных (сложноподчиненных) предложений.

(C) Н.Н. Ефремов, 2012 
Если в элементарных простых предложениях пространственное значение представляется непосредственно их пропозицией, то в полипредикативных конструкциях оно являет собой локативную связь и отношение двух или более пространственных ситуаций.

\section{2. Конструкции с дательным падежом}

Дательный падеж в отличие от других падежей, которые используются для выражения пространственных отношений, является наиболее употребительным, что обусловлено его многозначностью. Этим падежом обозначаются «смыслы, относящиеся к широкому диапазону ступеней абстракции» [Гузев, 1987, с. 83]. В якутском языке словами и конструкциями в дательном падеже наряду с собственно локативными значениями описываются также временные, дополнительные, причинные и другие смыслы.

Если в других тюркских языках, например, в шорском, турецком, в которых конструкции с дательным падежом в основном специализируются в выражении динамических пространственных отношений [Невская, 2005, с. 96-97; Кузнецов, 1999, с. 107], то якутские структуры с указанным падежом участвуют в образовании предложений как с динамическими, так и статическими пространственными значениями. Как известно, в тюркских языках для выражения статических пространственных отношений обычно используются конструкции с показателем местного падежа. В якутском языке данный падеж был вытеснен дательным и его функции перешли к последнему. Он «по существу выполняет функции дательного, направительного и местного [падежей]» [Грамматика, 1982, с. 135].

В зависимости от лексической семантики глагола, выступающего в качестве пространственного предиката, эта падежная форма может обозначать как конечную точку движения субъекта или перемещения объекта, так и их местонахождение.

Собственно-пространственное значение, как уже отмечалось, передается тогда, когда в качестве сказуемого используются глаголы с локальным смыслом, которыми формируются конструкции с различным локативным значением: например, локации (нахождение, прибывание, существование предмета в определенной точке пространства), адлокации (установление предметом - субъектом в результате перемещения, движения новых пространственных отношений), координата финиша (конечная точка движения субъекта / перемещения объекта), директива финиша (направление движения субъекта / перемещения объекта).

В нашей выборке встретились конструкции с дательным падежом, характеризующиеся, прежде всего, отношениями локации, адлокации, координаты финиша. Значение разрыва прежних пространственных отношений - делокация в подобных конструкциях обычно не получает специального обозначения. В необходимых случаях оно маркируется структурами с исходным падежом.

\section{1. Отношение локации}

Это отношение представляется в виде существования, местонахождения, позиции субъекта / объекта в пространстве. Названные типы локации характеризуются общим значением - отношением местонахождения, но отличаются от собственного местонахождения своими дифференциальными признаками.

Существование субъекта / объекта передается конструкциями с предикатами бытия (олор- 'жить', баар 'есть', 'имеется'). Подобные фразы характеризуются обычно планами прошедшего повествовательного, расширенного настоящего, что является их дифференциальным признаком.

(1) Ньыыкан ... Логлоор диэн сиргэ олорбута (НЭНЬ 5)

Ньыкан Логлоор диэ:н сир=гэ олор=бут=а 
Никон Логлор называть:CV местность=DAT жить=PP=3SG

'Никон жил в местности под названием Логлор';

(2) Хайа эркинигэр ... ойуулар бааллар (СФ 75)

хайа эркин=и=гэр ойуу =лар баал =лар

гора склон=POSS.3SG=DAT рисунок=PL есть=PFUT.3PL

'На склоне горы ... имеются рисунки'.

В класс рассматриваемых предложений также входят фразы со значением существования «определенного количества чего-л. в той или иной точке пространства» [Шилова, 2003, 2, с. 20]. Но от первых они отличаются семой «количественность», которая выражается «в общем виде, без помощи чисел» [ср.: Грамматика, 1982, с. 187].

(3) Саха сиригэр хальцы хаардаах кыһыннар, уу сут сайыннар_элбэхтэр эбээт (ИГ ХК 4)

саха сири=гэр халың хаар=даах кыһын=нар

якутия=DAT толстый снег $=$ POSSV зима $=$ PL

уу сут сайын=нар элбэх=тэр эбээт

голодный вследствие постоянных дождей лето $=$ PL $\quad$ много $=$ PL ведь

'В Якутии, ведь, бывает много зим с толстым снежным покровом, голодных летних времен вследствие постоянных дождей'.

Местонахождение субъекта / объекта описывается конструкциями с локализатором в дательном падеже, а их предикат выражается именами наличия и отсутствия (баар, суох). Их различительный признак - выражение событий, локализованных в плане того или иного времени (например, актуального настоящего, прошедшего незаконченного и др.).

(4) Ийэм дьиэђэ баар

ийэ $=$ м дьиэ=ђэ баар

мать $=$ POSS.1SG дом=DAT естьPFUT.3SG

'Мать дома';

(5) Кини Үлэтигэр суох

кини үлэ=ти=гэр суох

он работа=POSS.3SG=DAT нет3SG;

'Его нет на работе';

Иногда вместо имени наличия баар в форме имперфекта может употребляться недостаточный глагол э- в форме $-m$, у которого в подобных случаях проявляется былое бытийное значение в плане прошедшего незаконченного времени.

(6) Кини оччолорго Новосибирскайга эт:э

кини оччолорго Новосибирскай=га эт:э

Он в то время Новосибирск=DAT находиться / быть: 3SG. IMPRF

'Он в то время находился в Новосибирске'.

Отношение местонахождения может осложняться другими смыслами, например, адлокации, что обусловливается, прежде всего, лексико-грамматическим значением слова, заполняющего позицию сказуемого. Это, например, глаголы со значением размещения, поселения где-нибудь по приезде (например, $m_{Y c}$-).

(7) Эһиги уопсайгытызар түст үм (СР КТ 90)

эһиги уопсай $=$ гыт $=$ ыгар $\quad$ түс $=\mathbf{T}=\mathbf{Y M}$

ваш общежитие=POSS.2PL=DAT остановиться=PAST=1SG

'Я остановился в вашем общежитии (имплицитная пропозиция: прибытие кого-л откуда-л. куда-л. и эксплицитная пропозиция: размещение кого-л. где-л.)';

Положение (позиция) субъекта / объекта в пространстве представляется конструкциями с предикатами, выраженными глаголами позиции (олор- 'сидеть', cыm- 'лежать'; тур- 'стоять'). Их дифференциальный признак - выражение конкретных событий.

(8) Уол олоппоско олорор

уол олоппос $=$ ко 
мальчик табуретка=DAT сидеть=PFUT.3SG

'Мальчик сидит на табуретке';

(9) DIm yйатызар cbımap

ыт уйа $=$ ты=гар сыт=ар

собака конура=POSS.3SG=DAT лежать=PFUT.3SG

'Собака лежит в конуре';

(10) Бнах хотоңцо турар

ынах хотоң=но тур=ар

корова коровник=DAT стоять $=$ PFUT.3SG

'Корова стоит в коровнике'.

В (10) глагол тур- многозначный (ср.: ‘находиться', ‘содержаться’), соответственно, конструкциями с подобным предикатом может выражаться и пропозиция местонахождения или существования: 'Корова находится / содержится в коровнике'. В якутском языке глагол тур- в отличие от других глаголов позиции характеризуется грамматикализованностью, и участвует в образовании и глагольных аналитических конструкций с различным аспектуальным значением [Харитонов, 1960, с. 62-65]. В других тюркских языках Сибири, например, в тувинском турявляется одним из активных средств формирования аналитических аспектуальных форм [Шамина, Ондар, 2003, с. 63-64 и др.].

\section{2. Отношение адлокации, координаты финиша}

Конструкциями с дательным падежом передается также движение / перемещение кого-л. / чего-л. куда-л. Это значение имеет ряд семантических разновидностей, которые обусловливаются лексико-семантическим содержанием структур, представляющих участников (прежде всего, предикат) динамической пространственной ситуации.

Предикат дативных конструкций обсуждаемого пространственного типа выражается определенными лексико-семантического подгруппами глаголов однонаправленного движения, ориентированного, прежде всего, относительно конечного пункта. Это, в основном, глаголы ухода, прибытия, приближения, проникновения, выхода куда-л.

Уход представляется глаголами бар- 'идти', ‘уходить', ‘уезжать' айаннаа'отправляться в путь, дорогу, ездить'; прибытие - глаголами тиий- 'добираться до кого-/чего-л’, кэл- приходить, приезжать; прибывать; являться; подходить; наступать; приближение - глаголом чугаһаa 'приближаться, подходить', проникновение - глаголом киир- 'входить, заходить'; выход - глаголом тађыс- 'выходить'. Если глаголы ухода и прибытия составляют группу глаголов общего движения / перемещения куда-л., то глаголы проникновения и выхода представляют группу глаголов конкретизированного движения / перемещения. Данные глаголы являются основными единицами названных лексико-семантических подгрупп глаголов движения, куда входят также и другие глаголы. Рассмотрим конструкции обсуждаемого семантического типа в соответствии с их предикатами, которые характеризуются актантами в дательном и основном падеже.

\section{Конструкции с бар-}

Данный глагол многозначный, и в обсуждаемых конструкциях употребляется второй лексико-семантический вариант (ЛСВ-2) 'передвигаться из одного пункта в другой' [Толковый словарь, 2005, с. 184-185]. При этом исходный пункт движения в таких конструкциях выражается контекстуально. А движение субъекта, ориентированное к конечному пункту движения, может осложняться целевым оттенком. 
(11) Кинилэр Чучур Мурааңца бардылар (НЗ КДУ 141).

кини=лэр Чучур Мурааң=на бар=д=ылар

он=PL Чучур Муран $=\mathbf{D A T}$ пойти $=\mathrm{PAST}=3 \mathrm{PL}$

'Они пошли на Чучур Муран (целью дойти туда).

Конструкции ухода субъекта куда-л. представляются и производными глаголами, образованными от имен, обозначающих конечный пункт перемещения (например, балыbыha ‘больница' + -лаa - балыbыhaлаa- 'пойти в больницу'):

(12)... бу эрэйдээх балыыhалаабыт (НЗ КДУ 118)

'... этот бедняжка пошел в больницу'.

В якутском языке значение 'ехать', 'поехать' - двигаться куда-н. при помощи каких-н. средств передвижения; отправляться куда-н., передвигаясь при помощи каких-н. средств передвижения - не имеет лексического выражения, потому оно определяется характером лексического наполнения состава предложения или контекстуально. Обычно в подобном значении часто употребляется глагол айаннаa- (< айан 'дальняя поездка', 'дальний путь', 'дальнее направление' +-лаa). ЛСВ этого глагола обозначают следующие значения: 'совершать дальнюю поездку, путешествовать', 'направляться куда-л. (обычно далеко, с особой целью; если небольшое расстояние - медленно, с трудом)' [Толковый словарь, 2004, с. 311312]. Однако в семантической структуре и данного глагола нет семы «средство передвижения». Ср.:

(13) Aйатыгар айаннаата (АИС ТА 2 273)

айа $=$ ты $=$ гар айаннаa $=\mathrm{T}=\mathrm{a}$

самострел=POSS.3SG=DAT направляться=PAST=3SG

'Он направился к своим самострелам (проверять)'.

\section{Конструкции с тиий-}

Этот глагол также многозначен, и в качестве предиката дативных конструкций движения используется основной ЛСВ 'добираться, достигать' [Якутскорусский словарь, 1972, с. 382]. В подобных конструкциях целевой оттенок проявляется сильнее, чем в структурах с бар-:

(14) Дьиэбитигэр тиийдибит (СР КТ 51)

дьиэ $=$ бит $=$ игэр тиий $=$ д $=$ ибит

дом=POSS.1PL=DAT дойти=PAST $=\mathbf{1 P L}$

'Мы дошли до своего дома'.

\section{Конструкции с кэл-}

В рассматриваемых конструкциях имеют место два ЛСВ этого глагола: ЛСВ-1 - 'приходить, приезжать, прибывать, подходить'; ЛСВ-2 - 'оказаться, очутиться где-л.' [Толковый словарь, 2008, с. 465]. В отличие от структур с тиийв обсуждаемых конструкциях выражается не значение 'дойти до какого-н. места', а 'прибытие куда-л'.

(15) Дьиэтигэр кэлбитэ (НЗ КДУ 104)

дьиэ $=$ ти $=$ гэр кэл $=$ бит $=$ э

дом=POSS.3PL=DAT придти=PP=3SG

'Он пришел в свой дом'.

\section{Конструкции с чуzаһaa-}

Движение куда-л. может обозначаться и как приближение к конечному пункту, что выражается лексической семантикой глагольного сказуемого чугаһaa-:

(16) Сэксэгэ улам_чугаһаан истибит (ТС ТА 201)

сэксэ $=$ гэ улам чугаһ: аан ис $=\mathrm{T}=$ ибит

бугорок=DAT постепенно приближаться:CV AUX=PAST=1PL

'Мы стали постепенно приближаться к бугорку'. 


\section{Конструкции с киир-}

Конструкции с предикатом, выраженным многозначным глаголом киир-, в зависимости от семантики локализатора формируют ряд разновидностей пространственных предложений.

Проникновение кого-/чего-л. внутрь объемного пространства:

(17) [Хоско] Сатакин киирэн кэлбитэ (ЭЭ МЫ 18)

Сатакин киир $=$ эн кэл $=$ бит $=$ э

Сатакин входить $=\mathrm{CV}$ придти $=\mathrm{PP}=3 \mathrm{SG}$

'[В комнату] Вошел Сатакин'.

Прибытие кого-л. к кому-л., находящемуся в помещении, с определенной целью:

(18) Уйбааңңңа киирдим

Уйбааң=ңа киир $=$ д $=$ им

Иван:DAT зайти= PAST=1SG

' Я зашел к Ивану'.

Перемещение из открытого пространства в закрытое (например, в лес):

(19) Дьон ... түүң ойуурга киирэн кэллилэр (ЭЭ МЫ 262)

дьон түң ойуур=га киир=эн кэл=ли=лэр

люди глухой лес=DAT входить $=\mathrm{CV}=3 \mathrm{PL}$ приходить $=\mathrm{PAST}=3 \mathrm{PL}$

'Люди вошли ... в глухой лес'.

Перемещение кого- /чего-л с более высокого места куда-л. в низину (например, в реку, на озеро, в алас):

(20) Кыһыллар бастаан иһэр аттаахтара «Киэптээни» алааска киирдилэр (ЭЭ МЫ 261)

кыһыл=лар бастаа $=$ H иһ=эр аттаах $=$ тара киэптээни красный=РLидти впереди $=\mathrm{CV} \quad \mathrm{AUX}=\mathrm{PFUT} \quad$ кептэни

$$
\text { алаас=ка киир }=\text { ди=лэр }
$$

всадник $=$ POSS.3PL алас $=$ DAT $\quad$ входить $=$ PAST $=3 \mathrm{PL}$

'Авангард красных всадников спустился в алас Кептяни'.

Перемещение в центр (из периферии):

(21) Григорий Иванович ... куоракка киирбитэ (НЗ КДУ 141)

Григорий Иванович куорак=ка киир=бит=э

Григорий Иванович город=DAT зайти / пойти=PP=3SG

'Григорий Иванович ... п поехал в город (из деревни)'.

Заселение жилища:

(22) Саңа дьиэђэ киирдибит

саңа дьиэ=ђэ киир=ди=бит

новый дом $=\mathrm{DAT}$ заселяться $=\mathrm{PAST}=1 \mathrm{PL}$

'Мы заселились в новый дом'.

\section{Конструкции с тађыс-}

Эти конструкции в отличие от структур с киир- описывают перемещение субъекта верх, из замкнутого пространства в открытое пространство и т.п.

Перемещение верх:

(23) [хайа]...үөһээ былыкка тахсан...(Н3 КДУ 142)

үөһээ былык=ка тахс:ан

наверх облако=DAT подниматься:CV

'[гора] поднявшись наверх на облако'.

Перемещение из постоянного места жительства на временное место с определенной целью:

(24) ... вьаллара бары сайылыктарыгар тахсыбыттара (ЭЭ МЫ 94)

ыал=лара $\quad$ бары сайылык=тары=гар тахс:ыбыт=тара

семьи=POSS.3PL все летник=POSS.3PL=DAT переехать: PP=3PL 
‘...все семьи (данной местности) переехали в летник’.

В каузативных конструкциях с пространственным значением описывается перемещение объекта в другую точку пространства под воздействием субъекта высказывания (каузатора). Объект перемещения выражается именем существительным в винительном падеже, поэтому эти структуры в отличие от некаузативных являются четырехактантными.

В нижеследующей каузативной конструкции (25) со структурой в форме дательного падежа обозначается конечный пункт перемещения объекта и каузатора (ac acmblblp дbиэ 'дом для приготовления пищи'), предикат со значением перемещения кого-/чего-л. из замкнутого пространства (жилища) куда-л. выражен каузативным глаголом mahaap- (< тас 'наружный, внешний' + -aаp [Пекарский, 1959, стл. 2589]) 'выводить'. Употребление подобного предиката обусловлено конситуацией приводимого высказывания, так как движение осуществляется из основного локума (жилого помещения) в периферийный (подсобное помещение). Объект перемещения обозначается собственным именем (в винительном падеже), сказуемое выражено каузативным глаголом. При этом деепричастие ыңыыран обозначает образ действия - стимул перемещения объекта. 12)

(25) Хабыас Мэхээһи ... ас астыыр дыиэлэригэр ыңңыран таһаарда (ФЗ КК

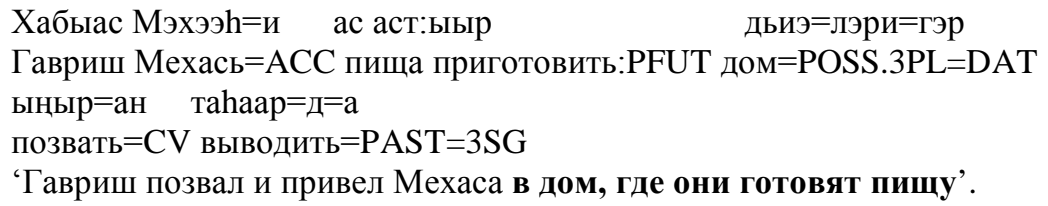

\section{3. Локативные сложноподчиненные предложения с показателем дательного падежа}

В сложноподчиненных предложениях (СПП) рассматриваемого типа показателем дательного падежа формируются зависимые предикаты, выраженные причастиями или другими предикативными именами (например, наличия - баaр 'есть, имеется'). Они в отличие от ЭПП имеют редкое употребление и используются для актуализации зависимого события.

В СПП с зависимым предикатом баap=1/2/3SG/PL=DAT обычно описывается изменение положения субъекта в пространстве и его локация, что определяется из контекста.

(26) Сэмэн кэлэн,( кириэһилэ баарыгар) олорбута (XС 197810 6)

Сэмэн кэл=эн кириэһилэ баар $=\mathbf{ы}=\mathbf{r a p}$

Семен придти $=\mathbf{C V}$ кресло имеется $=$ POSS.3SG=DAT

олор $=$ бут $=$ a

сидеть $=$ PP=3SG

'Семен пришел и сел на кресло, которое (здесь) было'.

Высказывание (26) характеризуется тремя предикативными единицами, из которых препозитивная и постпозитивная моносубъектные, интерпозитивная разносубъектная. Препозитивной предикативной единицей описывается прибытие субъекта, что передается деепричастным предикатом (кэл=эн) в сочетании с собственным именем (Сэмэн). Изменение положения этого субъекта в пространстве обозначается сказуемым главной части (олорбута) локативной монофинитной бипредикативной конструкции с пространственным значением. Зависимой частью данного предложения описывается существование, наличие предмета (кресла), а его местонахождение (в комнате) устанавливается из контекста. Это предложение переводится на русский язык атрибутивно-локативным СПП, где непосредственное представление описываемого события не получает языкового выражения, 
ибо оно является функционально-коммуникативной особенностью обсуждаемых якутских конструкций.

(27) ... (бэс чагда элгээн үрдүгэр баарыгар) Үс балаакка турара (НЭНЬ: 39)

$$
\text { бэс чагда элгээн үрдүгэр баар=ыгар }
$$

сосняк озеро в долине речки POSTP быть=3SG.DAT

үс балаакка тур=ара

три платка стоять=IMPRF.3SG

'В сосновом бору, находящемся над озером в долине речки, стояли три палатки'.

В ГПЕ СПП (27) описывается местонахождение объектов в пространстве (в сосновом бору), представленном в качестве субъекта ЗПЕ. Основа данного ЗПЕ обозначает существование данного натурфакта (субъекта) над чем-то (озером). Такая конструкция, выражающая основу ЗПЕ, являет собой вариант суперэссивной модели [Шилова, 2003, 2, с. 13].

В СПП с адлокативным смыслом зависимые предикаты обычно выражаются причастиями настояще-будущего времени, образованными от пространственных глаголов со значением существования, местонахождения, а главный предикат обычно глаголом прибытия - тиий- 'подходить', 'подойти', 'прийти'. Такие предложения передаются на русский язык также определительно-локативными СПП.

(28) (Таһырдьа биир кыысччаан Үңнүүлээн курбачыйа сылдьарыгар)

Николай Габымев тиийэр (СР КТ 82)

таһырдьа биир кыыс=чаан үңкүүл=ээн курбачый=а

на улице одна девочка $=$ DIM танцевать $=\mathrm{CV}$ кружиться $=\mathrm{CV}$

сылдь:ар=ыгар Николай Габышев тиий=эр

AUX:PFUT=3SG.DAT Николай Габышев подходить=PFUT.3SG

'На улице Николай Габышев подходит к маленькой девочке, которая танцует, кружась'.

Вышерассмотренное предложение имеет функциональный эквивалент, оформленный определительной конструкцией с причастным оборотом, который переводится на русский язык той же атрибутивной структурой:

(29) Таһырдьа ҮңкүҮлээн курбачыйа сылдьар биир кыьсчааңңа

Николай Габышев тиийэр

таһырдьа үңкүүлээ=н курбачый=а сылдь:ap биир

на улице танцевать $=C V$ кружиться $=\mathrm{CV}$ AUX:PFUT.3SG одна

кыыс=чааң=ңа Николай Габышев тиий=эр

девочка=DIM=DAT Николай Габышев подходить=PFUT.3SG.

\section{Выводы}

Локативные конструкции с дательным падежом в якутском языке представляются в виде моно и поли/бипредикативных (сложноподчиненных) конструкций. В отличие от других тюркских языков подобными конструкциями описываются как статические, так и динамические пространственные отношения. Так, в пространственных монопредикативных конструкциях выражаются отношения локации, адлокации, координата-финиша. В полипредикативных конструкциях с показателем дательного падежа передаются в основном динамические отношения адлокация, координата финиша. В них описывается пространственные связи и отношения событий (пропозиций), которые оформляются той или иной моделью элементарной монопредикативной конструкции с локативным значением. Эти предложения характеризуются сравнительно редким употреблением, поскольку имеют определенные функционально-коммуникативные задания и, кроме того, наделены эквивалентами, выраженными причастными определительными конструкциями, которые являются наиболее типичными средствами выражения подобных отношений. 


\section{Литература}

Большой толковый словарь якутского языка / Под ред. П.А. Слепцова: В 15 т. Новосибирск, 2004-2008. T. I; II; V.

Грамматика современного якутского литературного языка. Фонетика и морфология. М., 1982.

Гузев В.Г. Очерки по теории тюркского словоизменения: Имя (На материале староанатолийско-тюркского языка). Л., 1987.

Кузнецов П.И. Учебник турецкого языка. М., 1999.

Невская И.А. Типология локативных конструкций в тюркских языках Сибири (на материале шорского языка): Автореф. дис. ... д-ра филол. наук. Новосибирск, 1997.

Невская И.А. Пространственные отношения в тюркских языках Южной Сибири (на материале шорского языка). Новосибирск, 2005.

Пекарский Э.К. Словарь якутского языка. М., 1959. Т. 1-3.

Толковый словарь якутского языка / Под ред. П.А. Слепцова. Новосибирск, 2004. T. I.

Толковый словарь якутского языка / Под ред. П.А. Слепцова. Новосибирск, 2005. T. II.

Харитонов Л.Н. Видовые формы глагола в якутском языке. М.,Л., 1960.

Шамина Л.А., Ондар Ч.С. Глагольные аналитические конструкции с первым причастным компонентом в тувинском языке. Новосибирск, 2003.

Шилова В.В. Пространственные модели элементарных простых предложений в ненецком языке. Новосибирск, 2003. Ч. 1-2.

Якутско-русский словарь. М., 1972.

\section{Список условных обозначений}

ACC - винительный падеж; AUX - вспомогательный глагол; CV - деепричастие; IMPRF - прошедшее незаконченное время; DAT - дательный падеж; DIM уменьшительно-ласкательный аффикс, IMPRF - прошедшее незаконченное время (имперфект); PAST - прошедшее время на -т; PFUT - причастие настоящебудущего времени; PL - множественное число; POSS - притяжательность; POSSV - имя обладания; POSTP - послелог; РP - причастие прошедшего времени на -быт; SG - единственное число; ( ) - линейная позиция зависимой предикативной единицы.

\section{Список условных обозначений текстовых источников}

АИС ТА 2 Анемподист Иванович Софронов. Талыллыбыт айымньылар (Избранные произведения). 2-с т. Дьокуускай, 1965.

ДТ С Дмитрий Таас. Сэһэннэр (Повести). Дьокуускай, 1990.

ИГ ХК Иван Гоголев. Хара Кыталык (Черный Стерх). Дьокуускай, 2008.

НЗ КДУ Николай Заболоцкай. Күн да уһун (День длинный). Дьокуускай, 1968.

НЭНь Норуот эмчитэ Ньықан (Народный целитель Никон). Дьокуускай, 2011.

СР КТ Семен Руфов. Куораттарга, тыаларга (В городах, сельской местности). Дьокуускай, 1976.

СФ Саха фольклора (Якутский фольклор). Дьокуускай, 1986.

TC ТА Тимофей Сметанин. Талыллыбыт айымньылар (Избранные произведения). Дьокуускай, 1969.

ФЗ КК Федот Захаров. Күчүмэђэй күннэр (Трудные дни). Дьокуускай, 1985.

ХС Хотугу Сулус (Полярная звезда).

ЭЭ МЫ Эрилик Эристиин. Маарыкчаан ыччаттара (Марыкчанская молодежь). Дьокуускай, 1983. 